\title{
Immunohistochemistry as a paramount tool in research of normal urothelium, bladder cancer and bladder pain syndrome
}

\author{
Daša Zupančič, Rok Romih \\ Institute of Cell Biology, Faculty of Medicine, University of Ljubljana, Slovenia
}

\begin{abstract}
The urothelium, an epithelium of the urinary bladder, primarily functions as blood-urine permeability barrier. The urothelium has a very slow turnover under normal conditions but is capable of extremely fast response to injury. During regeneration urothelium either restores normal function or undergoes altered differentiation pathways, the latter being the cause of several bladder diseases. In this review, we describe the structure of the apical plasma membrane that enables barrier function, the role of urothelium specific proteins uroplakins and the machinery for polarized membrane transports in terminally differentiated superficial umbrella cells. We address key markers, such as keratins, cancer stem cell markers, retinoic acid signalling pathway proteins and transient receptor potential channels and purinergic receptors that drive normal and altered differentiation in bladder cancer and bladder pain syndrome. Finally, we discuss uncertainties regarding research, diagnosis and treatment of bladder pain syndrome. Throughout the review, we emphasise the contribution of immunohistochemistry in advancing our understanding of processes in normal and diseased bladder as well as the most promising possibilities for improved bladder cancer and bladder pain syndrome management.
\end{abstract}

Key words: Urothelium; bladder cancer; bladder pain syndrome; uroplakins; keratins; retinoic acid; transient receptor potential channels; purinergic receptors.

Correspondence: Rok Romih, Institute of Cell Biology, Faculty of Medicine, University of Ljubljana, Vrazov $\operatorname{trg} 2$, 1000 Ljubljana, Slovenia.

Tel. +38615437683 - Fax: +38615437681 .

E-mail: rok.romih@mf.uni-lj.si

Contributions: DZ, manuscript writing, design and discussing; RR, manuscript planning, discussing, editing and proofreading; DZ, RR, planning, execution and analysis of studies.

Conflict of interest: The authors declare no potential conflict of interest. 


\section{Introduction}

The urothelium is a stratified epithelium of the lower urinary tract covering the renal pelvis, ureters, urinary bladder and proximal urethra. ${ }^{1}$ Bladder urothelium is composed of three distinctive cell layers, i.e. poorly differentiated basal cells, partially differentiated intermediate cells, and terminally differentiated superficial umbrella cells. The urothelium plus basal lamina and lamina propria form the mucosal layer of the bladder wall., ${ }^{2,3}$ The other two layers are the muscularis propria (detrusor) and the adventitia/serosa.

Functionally, normal urothelium forms a blood-urine permeability barrier against toxic metabolites and pathogenic bacteria in the urine. Transepithelial resistance of the urothelium is 10,000$75,000 \Omega \mathrm{cm}^{2}$, which is extremely high and puts urothelium among the tightest barriers in mammalian body. ${ }^{4}$ The barrier must be maintained during micturition cycles, particularly when bladder is stretched by filling with urine. ${ }^{2}$ This requirement is accomplished mainly by terminal differentiation of umbrella cells.

The ability of the bladder to perform its function of urine storage and voiding depends on the central nervous system receiving accurate information on the state of the bladder fullness, which was first described in 1933 by Denny-Brown and Robertson. ${ }^{5}$ Recent evidence suggests that sensory proteins like transient receptor potential (TRP) channels and purinergic $\mathrm{P} 2 \mathrm{X}$ receptors in the urothelium are activated by binding of ATP or upon distension, respectively. ${ }^{6,7}$ This leads to release of signaling molecules such as ATP, NO and acetylcholine from urothelium and their action on interstitial cells, afferent fibres and smooth muscle cells in the bladder wall. ${ }^{8,9}$ Therefore urothelium acts as a part of bladder sensory web, which coordinates the micturition cycle. ${ }^{10}$

The permeability barrier and sensory function of the urothelium are often compromised in bladder diseases like bladder cancer (BC) and bladder pain syndrome (BPS). Immunohistochemistry (IHC) provided crucial contribution to our comprehension of urothelial structure and function in health and disease. Data were obtained by IHC based on peroxidase reaction (IHC-Px), but the most informative were immunofluorescence (IF) and immunoelectron microscopy (IEM).

\section{Immunohistochemistry reveals the mysteries of normal urothelial differentiation}

Seminal transmission electron microscopy analyses done by Marian R. Hicks in the sixties revealed thickened plasma membrane of the bladder's luminal surface and of angular cytoplasmic vesicles, which suggested that these membrane are unusually rigid. ${ }^{11}$ Leopold G. Koss named this membrane asymmetric unit membrane (AUM). ${ }^{3}$ It was confirmed that AUM forms apical plasma membrane and fusiform vesicles (FVs) of the umbrella cells., ${ }^{2,12}$ The designation 'urothelial plaques' was coined to describe rigid AUM structure. ${ }^{13}$ Urothelial plaques cover up to $90 \%$ of the apical surface and they are separated by narrow hinge regions of unthickened symmetric membrane. ${ }^{14}$ Another evidence for this organisation came from scanning electron microscopy and atomic force microscopy, which showed that plaques are surrounded by microridges, which correspond to hinge regions. ${ }^{15-18}$ Isolation, freeze fracturing and quick-freeze/deep-etch demonstrated that urothelial plaques (diameter 0.2-0.5 $\mu \mathrm{m}$ ) contain hexagonally arranged 16nm intramembrane particles. ${ }^{19-21}$ Cryo-electron microscopy provided evidence that these particles create structural basis for urothelial permeability barrier. $^{22}$

Ground-breaking understanding of molecular structure of intramembrane particles came in the beginning of nineties with the discovery of 4 transmembrane proteins, uroplakins (UPs) Ia, Ib, II and IIIa by the group of Tung-Tien Sun. ${ }^{20,23-25}$ IHC-Px and IF confirmed their expression in umbrella cells and IEM showed their association with urothelial plaques ${ }^{17-19}$ (Figure 1). A model of UPs assembly into $16-\mathrm{nm}$ particles ${ }^{26}$ suggests that UPs acquire high mannose glycans and form two heterodimers (UPIa/UPII and $\mathrm{UPIb} / \mathrm{UPIII}$ ) in the endoplasmic reticulum..$^{27,28}$ These heterodimers exit from the endoplasmic reticulum and they are transported to the Golgi apparatus (GA). ${ }^{29,30}$ In the GA, specific glycosylation occurs, which causes conformational changes, thus allowing heterotetramer (UPIa/UPII + UPIb/UPIII) formation. ${ }^{31}$ In the transGolgi network (TGN), the prosequence of UPII is removed, triggering the oligomerization of 6 heterotetramers into one urothelial particle. $^{26,32}$ IEM revealed polarised transport of UPs from the TGN to the apical plasma membrane of the umbrella cell. A crucial necessity for such polarised transport are tight junctions of the umbrella cells. ${ }^{33}$ Combination of transmission electron microscopy, IEM, IF, freez-fracture and electron tomography
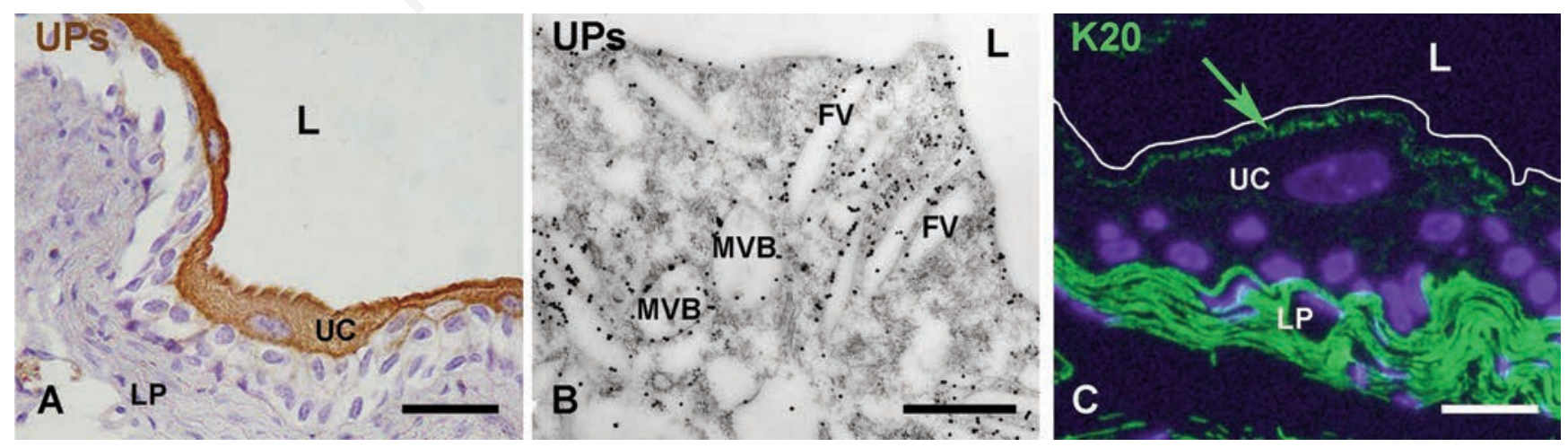

Figure 1. Normal urothelium of the mouse urinary bladder. A) IHC-Px of uroplakins (UPs) is positive (brown) in the superficial umbrella cells; B) IEM of UPs is positive in the membranes of fusiform vesicle, multivesicular bodies and in the apical plasma membrane of umbrella cell; C) IF of keratin K20 is positive (green arrow) in the subapical region of umbrella cell. Labelling of the lamina propria is unspecific. L, lumen; UC, umbrella cell; FV, fusiform vesicle; MVB, multivesicular body; LP, lamina propria; white line, location of the apical plasma membrane. Scale bars: A) $50 \mu \mathrm{m}$; B) $500 \mathrm{~nm}$; C) $20 \mu \mathrm{m}$. 
demonstrated the sequential steps of urothelial plaque formation in post-Golgi compartments. First, small rounded uroplakin-positive transporting vesicles detach from the TGN and subsequently fuse into immature FVs with slightly dilated profiles. With additional fusions and buddings, they mature into flattened FVs, which transport urothelial plaques toward the apical surface of the umbrella cells. $^{34,35}$ According to IF and IEM, FVs contain Rab8/11 and Rab27b/Slac2-a, which mediate apical transport along actin filaments by the action of myosin Va. FVs pass trajectorial network of $\mathrm{K} 20$ to reach the subapical region of the umbrella cells (Figure 1). ${ }^{36}$ This is followed by membrane tethering and a final step of SNARE mediated and MAL (myelin-and-lymphocyte protein) facilitated membrane fusion with the apical plasma membrane. ${ }^{37,38}$

To sum up, uroplakins and K20 are two major markers, which have to be analyzed by IHC, IF and IEM to assess differentiation stage of urothelial cells. Therefore, the detection of their expression and localisation is crucial to discriminate between normal and pathologically altered urothelium.

\section{How immunohistochemistry contributes to under- standing the bladder cancer}

The majority of $\mathrm{BC}$ are urothelial carcinomas. More than a half of them are papillomas or the papillary carcinomas (pTa, pT1), which have a relatively good prognosis. ${ }^{39}$ Squamous cell carcinomas have variable survival outcomes, while carcinoma in situ (CIS) can progress to muscle-invasive urothelial carcinoma (pT2) with poor prognosis. ${ }^{40}$ The most challenging feature of $\mathrm{BC}$ is its high recurrence rate, which is between $50 \%$ and $90 \%$ of cases. ${ }^{41}$

Somehow surprising is the finding that immunohistochemical labelling of UPs does not correlate with BC stage and grade..$^{42,43}$ However, IEM showed that despite the expression of UPs is preserved

their subcellular localization is changed in urothelial cancer cells. In contrast to normal superficial cells, they appear also in the basolateral plasma membrane, which points to altered regulation of membrane transports (Figure 2). ${ }^{44,45}$

Accepted diagnostic and prognostic markers for $\mathrm{BC}$ are changes of keratin expression profiles. For comparison, IF demonstrated the expression of K7, K8, K18 and K19 in all cell layers, small quantity of K5 in basal cells, K13 in basal and some intermediate cells and K20 only in umbrella cells in the normal urothelium. ${ }^{46-48}$ Normal K20 expression pattern is correlated with nonrecurrent tumours and it can therefore be used for objective differential diagnosis between papillomas and carcinomas. ${ }^{49}$ Increased expression of $\mathrm{K} 20$ in all urothelial cell layers is distinctive feature of CIS,${ }^{50}$ while intense IHC-Px staining of K8 and K18 might point to invasive cancer. ${ }^{49}$ Furthermore, the loss of K13 is associated with high cancer grade and stage, while de novo expression of $\mathrm{K} 14$ may indicate squamous differentiation of urothelial cells and an unfavourable outcome for patients. ${ }^{49}$

It turned out that keratin immunolabelling is important for the studies of BC progression and recurrence, which both rely on cancer stem cells (CSCs). Their identification and immunolocalization remain elusive, mainly because it is not clear weather cancer originate form one or more subpopulations of CSCs. A subset of $\mathrm{K} 5$, K14 and sonic hedgehog positive basal cells were proposed to be the urothelial CSCs. ${ }^{51}$ Furthermore, Lin et al. suggested that $\mathrm{K} 5$-positive, K7-negative basal cells with constitutive expression of $\beta$-catenin were the possible CSCs. ${ }^{52}$ In accordance with these results, Shin et al. discovered that K5-positive basal cells, which also express sonic hedgehog, were necessary for CIS and invasive carcinoma development. ${ }^{53}$ The origin of urothelial carcinomas was challenged by lineage tracing studies, which showed that papillary carcinoma arises from intermediate cells, while CIS and muscleinvasive carcinoma arise through the transformation of K5-negative basal cells. ${ }^{51}$

Several pieces of evidence show that the retinoic acid (RA) signalling pathway is often compromised in carcinomas. ${ }^{54,55}$ For example, due to low intake of vitamin A (a generic term referring to a group of retinoids, such as retinol, retinal and RA), normal urothelium is replaced by urothelial squamous metaplasia, a precancerous stage, which may progress to squamous carcinoma. ${ }^{5}$ Additionally, several epidemiological studies and meta-analyses show that high vitamin $\mathrm{A}$ intake and high vitamin A serum levels are associated with lower risk of $\mathrm{BC}$ in humans. ${ }^{57-59} \mathrm{In}$ an animal model of early bladder carcinogenesis, we demonstrated that vitamin A-rich diet altered RA signalling and decreased atypia and apoptosis of urothelial cells. ${ }^{60}$ Moreover, IF revealed that during early bladder carcinogenesis, lecithin retinol acyltransferase (LRAT), which transforms retinol to inactive retinyl esters, is
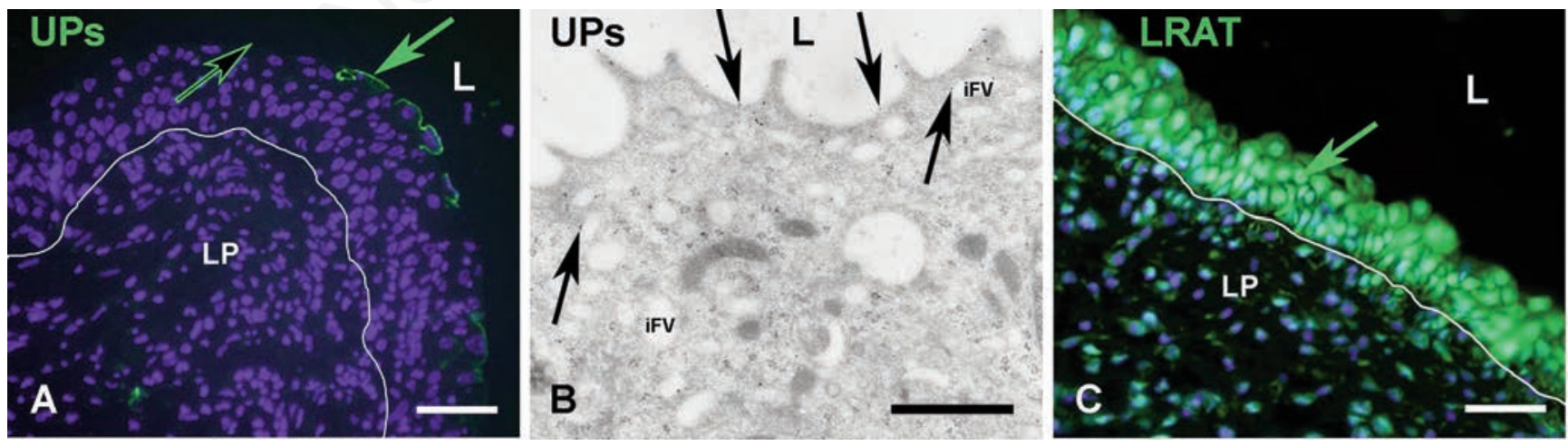

Figure 2. Animal model of bladder carcinogenesis induced by N-Butyl-N-(4-hydroxybutyl)nitrosamine (BBN). A) IF of uroplakins (UPs) is positive (green arrow) or negative (black arrow) in the apical plasma membrane of superficial urothelial cells after 10 weeks of BBN treatment; B) IEM of UPs is positive (arrows) in the membranes of immature fusiform vesicle (iFV) and in the apical plasma membrane of superficial urothelial cell after 5 weeks of BBN treatment; C) IF of lecithin retinol acyltransferase (LRAT) is positive (green) in the urothelium after 2 weeks of BBN treatment; LRAT is present in the cytoplasm of the urothelial cells and also in their nuclei (green arrow). L, lumen; UPs, uroplakins; iFV, immature fusiform vesicle; LP, lamina propria; white line, approximate location of basal lamina. Scale bars: A,C) $50 \mu \mathrm{m}$; B) $1 \mu \mathrm{m}$. 
translocated from cytoplasm of urothelial cells into their nuclei (Figure 2) ${ }^{60}$ We assume that LRAT exerts its tumour-suppressing role in the nuclei of urothelial cells. ${ }^{61}$ This notion is supported by the study of Boorjian et al., which showed by IHC-Px that LRAT is inversely correlated to tumour stage in BC. ${ }^{62}$ Although various findings from in vivo and in vitro models of $\mathrm{BC}$ demonstrate a potential for the use of synthetic and natural retinoids for BC prevention and treatment, the successful clinical trials are needed before they can be used in clinical settings.

\section{Bladder pain syndrome remains a major challenge for immunohistochemistry}

The urothelial-associated sensory web is affected in BPS. BPS belong to a group of bladder diseases under the term interstitial cystitis/bladder pain syndrome (IC/BPS). ${ }^{63,64}$ Main presenting symptoms of BPS are frequency, urgency, nocturia, and bladder pain, which often increases as the bladder fills. Despite unknown etiology, difficult diagnosis and lack of effective treatment (https://uroweb.org/, https://www.auanet.org/), aberrant urothelial cell differentiation, together with accompanying changes in sensory protein expressions are unifying hallmarks of BPS that are stud- ied by IHC. BPS is associated with incomplete urothelial differentiation as demonstrated by IEM that showed lower expression of UPs and absence of urothelial plaques in the apical plasma membrane. ${ }^{65-67}$ This may lead to a leaky barrier followed by enhanced signalling from the urothelium. ${ }^{65}$ TRP channels and $\mathrm{P} 2 \mathrm{X}$ receptors are among the candidates to play a role in BPS since they are dysregulated during various micturition-related disorders. ${ }^{68}$ TRP channels are nonspecific cation channels that are permeable to $\mathrm{Ca}^{2+}$ and might act as sensors of stretch and/or chemical irritation. The TRP channel superfamily consists of subfamilies TRPA (ankyrin), TRPC (canonical), TRPM (melastatin), TRPML (mucolipin), TRPN (no mechanopotential), TRPP (polycystin) and TRPV (vanilloid). ${ }^{69} \mathrm{P} 2 \mathrm{X}$ receptors are membrane ion channels preferably permeable to sodium, potassium and calcium. Various homo- and hetero-trimers of P2X1-P2X7 subunits associate to form a functional ion channels that open upon binding of extracellular ATP. Almost all subtypes of TRPV channels and P2X receptors were shown in the bladder wall by various methods, but we consider here only those that were immunohistochemically demonstrated in the urothelium.

Several members of TRP superfamily (e.g. TRPV1, TRPV4, TRPV2, TRPM4, TRPM7, TRPM8, TRPA1, TRPC1 and TRPC4) were shown in normal urothelium by IHC..$^{70}$ The majority of stud-
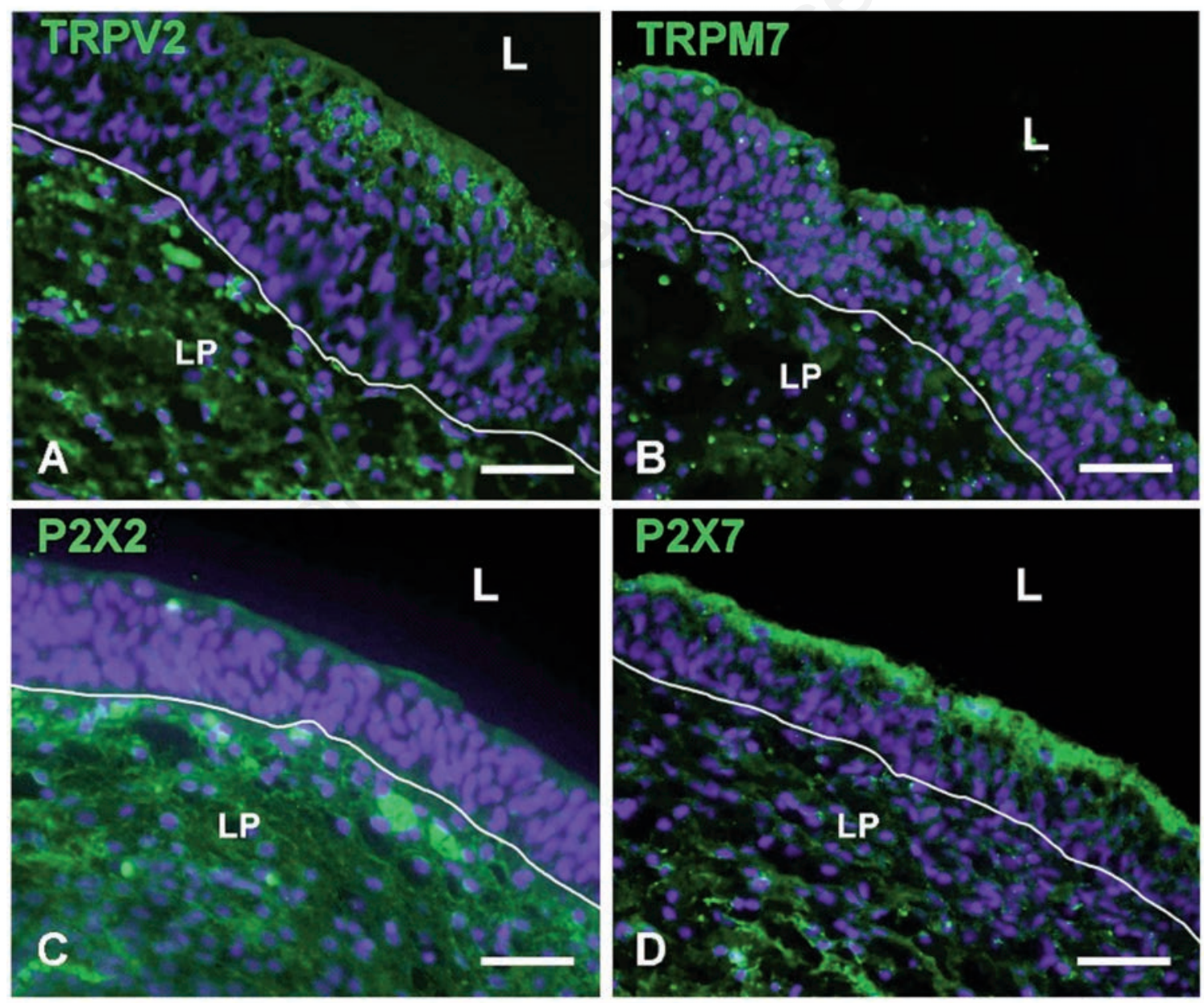

Figure 3. Our preliminary IF results on normal human urothelium of the urinary bladder. A) IF of TRPV2 is positive (green) in the superficial layers of the urothelium and in some areas of the lamina propria; B) IF of TRPM7 is positive (green) in the superficial layers of the urothelium; C) IF of P2X2 is weakly positive (green) in the superficial urothelial cells; D) IF of P2X7 is positive (green) in the superficial layers of the urothelium. L, lumen; LP, lamina propria; white line, approximate location of basal lamina. Scale bars: $100 \mu \mathrm{m}$. 
ies focus on TRPV1 and TRPV4. TRPV1 is essential for pain sensation associated with BPS, while TRPV4 is the main urothelial mechanosensor, which is activated by bladder distension..$^{71}$ There is still a controversy about TRPV1 expression in urothelium, since variable labelling results were reported by different groups. ${ }^{72-76}$ For example, a weak anti-TRPV1 labelling in superficial urothelial layer by IF. ${ }^{74}$ However, a similar staining pattern was observed in the urothelium of wild-type and TRPV1 knockout mice, which shows that currently used anti-TRPV1 antibodies can cause an unspecific labelling. ${ }^{77}$ Several studies showed altered expression of TRPV1 in patients with BPS as well as in animal models, but until now only one study demonstrated this by $\mathrm{IF}^{74,75,78,79}$ On the other hand, there is more consistency about TRPV4 localization in the normal urothelium, particularly in the basal cell layer. ${ }^{76,80,81}$ IEM further showed that TRPV4 is localized near the basal plasma membranes adjacent to the basal lamina. ${ }^{73}$ Although some studies reported on important role of TRPV4 in BPS, ${ }^{82,83}$ no IHC confirmation is available, yet. Regarding other members of TRP family, IF studies showed that TRPV2 and TRPM4 were prominently localized to the umbrella cell apical plasma membrane, TRPC4 and TRPV4 on their abluminal surfaces, while TRPC1, TRPM7, and TRPML1 in their cytoplasm (Figure 3). ${ }^{73,76,80,84}$ To the best of our knowledge, the studies of their possible contributions to BPS were not performed.

All of seven P2X receptors subtypes were expressed throughout the urothelium as suggested by an IF study on feline bladders. ${ }^{85}$ In comparison, clear P2X7, less distinct P2X2 and weaker P2X3 labelling was observed in the normal human urothelium (Figure 3). ${ }^{86}$ In the mouse urothelium, IF revealed that $\mathrm{P} 2 \mathrm{X} 7$ receptor is confined to the superficial urothelial cells. ${ }^{87}$ Additionally, in the rat urothelium, P2X7 and P2X4 are expressed both intracellularly and on the apical surface. ${ }^{8}$ The most studied member of P2X family is P2X3, yet again, the IF results are inconsistent about its urothelial expression, since studies report positive, weak or negative labelling. ${ }^{85-87,89-92}$ While there was a marked reduction in P2X1 receptor staining observed in feline interstitial cystitis ${ }^{85}$ studies on human biopsy samples from patients with BPS revealed that the expression of P2X2 and P2X3 is increased in the urothelium..$^{93,94}$ Moreover, P2X3 expression is abnormally upregulated in response to stretch in urothelial cells isolated from patients with BPS. ${ }^{95,96}$

Since TRPV1 and P2X3 represent the most important therapeutic targets for BPS, their adequate immunolocalization is of huge importance. Unfortunately, as mentioned above, IHC is still generating confusing results about the presence and distribution of TRP channels and P2X receptors in the urothelium. The reasons for that are diverse, but they probably include low expression levels of these proteins, poor specificity of antibodies, lack of adequate controls and the fact that the urothelium is particularly susceptible to nonspecific adsorption of antibodies. ${ }^{97}$ Moreover, other experimental approaches (e.g., immunoblotting, RT-PCR, in situ hybridization, fluorescently activated cell sorting, functional and pharmacological assays) introduced additional controversies regarding the expression of these and other sensory and signalling proteins in the urothelium. ${ }^{97}$

\section{What more can immunohistochemistry do in the field of urothelial biology?}

Despite a vast amount of knowledge on urothelial biology gained in the recent years, there are still many open questions. Some of them, which are closely related to the discussions above, emerged also from our work and they are briefly described here.

In contrast to well established pathway of apical plasma membrane biosynthesis in umbrella cells, less understood remain the function, mechanism and regulation of the endocytosis of UPs. It is possible that in umbrella cells a small fraction of fusiform vesicles is formed by urothelial plaque internalization upon voiding. Yet, we have shown that apical plasma membrane is internalized mainly from hinge regions by small endocytic vesicles..$^{98,99}$ Internalized UPs become integrated into the membranes of multivesicular bodies (Figure 1B) to be later degraded in lysosomes. Recently it was shown that sorting nexin Snx31 plays an active role in the regulation of UPs degradation. ${ }^{100}$ It seems that increased UPs synthesis, together with the rearrangement of actin filaments and microtubules, hinder apical endocytosis. ${ }^{98,101}$ Moreover, Khandelwal et al. showed that apical endocytosis occurs via nonclathrin pathway that requires RhoA and dynamin $2 .{ }^{102}$

We have gained some insights into altered RA signalling during early bladder carcinogenesis (Figure 2C), but there are no data about RA signalling in developed urothelial carcinomas. ${ }^{60} \mathrm{We}$ have discussed the role of P2Xs and TRPs, particularly in BPS patients, where we have seen that the IHC results are inconclusive or preliminary (Figure 3). Other receptors and channels involved in urothelial signalling have been reported, ${ }^{9}$ including adrenoreceptors, muscarinic and nicotinic receptors. ${ }^{103}$ However, with all of them there is the same problem of conflicting IHC results. The problem of inconclusive localization results can be resolved in two ways. First, by the production of more specific antibodies against these proteins, which will be suitable also for IEM. Second, by applying new or improved techniques, such as cryosections according to the Tokuyasu, freeze-fracture replica immunolabelling, combined lectin- and immuno-histochemistry and correlative light and electron microscopy. ${ }^{104-108}$

We believe that IHC will remain indispensable for bladder research in the future, not only for resolving basic biological questions, but also for helping find and implement new diagnostic and treatment strategies for BC, BPS and other bladder disorders.

\section{Acknowledgments}

The authors acknowledge financial support from the P3-0108, J7-2594, J3 2521, MRIC UL IP-0510 Infrastructure program of the Slovenian Research Agency ARRS.

\section{References}

1. Romih R, Korosec P, de Mello W, Jr., Jezernik K. Differentiation of epithelial cells in the urinary tract. Cell Tissue Res 2005;320:259-68.

2. Hicks RM. The mammalian urinary bladder: an accommodating organ. Biol Rev Camb Philos Soc 1975;50:215-46.

3. Koss LG. The asymmetric unit membranes of the epithelium of the urinary bladder of the rat. An electron microscopic study of a mechanism of epithelial maturation and function. Lab Invest 1969;21:154-68.

4. Lewis SA, Diamond JM. Na+ transport by rabbit urinary bladder, a tight epithelium. J Membr Biol 1976;28:1-40.

5. Denny-Brown D, Robertson EG. On the physiology of micturition. Brain 1933;56:149-90.

6. Apodaca G. The uroepithelium: not just a passive barrier. Traffic 2004;5:117-28.

7. Birder LA. More than just a barrier: urothelium as a drug target for urinary bladder pain. Am J Physiol Renal Physiol 2005;289:F489-95.

8. Burnstock G, Cocks T, Crowe R, Kasakov L. Purinergic innervation of the guinea-pig urinary bladder. $\mathrm{Br} \mathrm{J}$ Pharmacol 
1978;63:125-38.

9. Winder M, Tobin G, Zupancic D, Romih R. Signalling molecules in the urothelium. Biomed Res Int 2014;2014: 297295.

10. Apodaca G, Balestreire E, Birder LA. The uroepithelial-associated sensory web. Kidney Int 2007;72:1057-64.

11. Hicks RM. The fine structure of the transitional epithelium of rat ureter. J Cell Biol 1965;26:25-48.

12. Porter KR, Kenyon K, Badenhausen S. Specializations of the unit membrane. Protoplasma 1967;63:262-74.

13. Caruthers JS, Bonneville MA. Isolation and characterization of the urothelial lumenal plasma membrane. J Cell Biol 1977;73:382-99.

14. Hicks RM, Ketterer B. Hexagonal lattice of subunits in the thick luminal membrane of the rat urinary bladder. Nature 1969;224:1304-5.

15. Zupancic D, Romih R, Robenek H, Zuzek Rozman K, Samardzija Z, Kostanjsek R, et al. Molecular ultrastructure of the urothelial surface: insights from a combination of various microscopic techniques. Microsc Res Tech 2014;77:896-901.

16. Walz T, Häner M, Wu XR, Henn C, Engel A, Sun TT, et al. Towards the molecular architecture of the asymmetric unit membrane of the mammalian urinary bladder epithelium: a closed "twisted ribbon" structure. J Mol Biol 1995;248:887900.

17. Veranic P, Romih R, Jezernik K. What determines differentiation of urothelial umbrella cells? Eur J Cell Biol 2004;83:2734.

18. Romih R, Veranic P, Jezernik K. Appraisal of differentiation markers in urothelial cells. Appl Immunohistochem Mol Morphol 2002;10:339-43.

19. Kachar B, Liang F, Lins U, Ding M, Wu XR, Stoffler D, et al. Three-dimensional analysis of the $16 \mathrm{~nm}$ urothelial plaque particle: luminal surface exposure, preferential head-to-head interaction, and hinge formation. J Mol Biol 1999;285:595608.

20. Wu XR, Manabe M, Yu J, Sun TT. Large scale purification and immunolocalization of bovine uroplakins I, II, and III. Molecular markers of urothelial differentiation. J Biol Chem 1990;265:19170-9.

21. Wu XR, Lin JH, Walz T, Haner M, Yu J, Aebi U, et al. Mammalian uroplakins. A group of highly conserved urothelial differentiation-related membrane proteins. J Biol Chem 1994;269:13716-24.

22. Min G, Zhou G, Schapira M, Sun TT, Kong XP. Structural basis of urothelial permeability barrier function as revealed by Cryo-EM studies of the $16 \mathrm{~nm}$ uroplakin particle. J Cell Sci 2003;116:4087-94.

23. Yu J, Manabe M, Wu XR, Xu C, Surya B, Sun TT. Uroplakin I: a $27-\mathrm{kD}$ protein associated with the asymmetric unit membrane of mammalian urothelium. J Cell Biol 1990;111:120716.

24. Wu XR, Lin JH, Walz T, Häner M, Yu J, Aebi U, et al. Mammalian uroplakins. A group of highly conserved urothelial differentiation-related membrane proteins. J Biol Chem 1994;269:13716-24.

25. Yu J, Lin JH, Wu XR, Sun TT. Uroplakins Ia and Ib, two major differentiation products of bladder epithelium, belong to a family of four transmembrane domain (4TM) proteins. J Cell Biol 1994;125:171-82.

26. Hu CC, Liang FX, Zhou G, Tu L, Tang CH, Zhou J, et al. Assembly of urothelial plaques: tetraspanin function in membrane protein trafficking. Mol Biol Cell 2005;16:3937-50.

27. Deng FM, Liang FX, Tu L, Resing KA, Hu P, Supino M, et al. Uroplakin IIIb, a urothelial differentiation marker, dimerizes with uroplakin Ib as an early step of urothelial plaque assembly. J Cell Biol 2002;159:685-94.

28. Liang FX, Riedel I, Deng FM, Zhou G, Xu C, Wu XR, et al. Organization of uroplakin subunits: transmembrane topology, pair formation and plaque composition. Biochem J 2001;355:13-8.

29. Tu L, Sun TT, Kreibich G. Specific heterodimer formation is a prerequisite for uroplakins to exit from the endoplasmic reticulum. Mol Biol Cell 2002;13:4221-30.

30. Tu L, Kong XP, Sun TT, Kreibich G. Integrity of all four transmembrane domains of the tetraspanin uroplakin $\mathrm{Ib}$ is required for its exit from the ER. J Cell Sci 2006;119:5077-86.

31. Lin JH, Wu XR, Kreibich G, Sun TT. Precursor sequence, processing, and urothelium-specific expression of a major 15$\mathrm{kDa}$ protein subunit of asymmetric unit membrane. J Biol Chem 1994;269:1775-84.

32. Hu CC, Bachmann T, Zhou G, Liang FX, Ghiso J, Kreibich G, et al. Assembly of a membrane receptor complex: roles of the uroplakin II prosequence in regulating uroplakin bacterial receptor oligomerization. Biochem J 2008;414:195-203.

33. Lewis SA. Everything you wanted to know about the bladder epithelium but were afraid to ask. Am J Physiol Renal Physiol 2000;278:F867-74.

34. Hudoklin S, Jezernik K, Neumüller J, Pavelka M, Romih R. Electron tomography of fusiform vesicles and their organization in urothelial cells. PLoS One 2012;7:e32935.

35. Hudoklin S, Jezernik K, Neumuller J, Pavelka M, Romih R. Urothelial plaque formation in post-Golgi compartments. PLoS One 2011;6:e23636.

36. Veranic P, Jezernik K. Trajectorial organisation of cytokeratins within the subapical region of umbrella cells. Cell Motil Cytoskeleton 2002;53:317-25.

37. Kong XT, Deng FM, Hu P, Liang FX, Zhou G, Auerbach AB, et al. Roles of uroplakins in plaque formation, umbrella cell enlargement, and urinary tract diseases. J Cell Biol 2004; 167:1195-204.

38. Zhou G, Liang FX, Romih R, Wang Z, Liao Y, Ghiso J, et al. MAL facilitates the incorporation of exocytic uroplakin-delivering vesicles into the apical membrane of urothelial umbrella cells. Mol Biol Cell 2012;23:1354-66.

39. Epstein JI, Amin MB, Reuter VR, Mostofi FK. The World Health Organization/International Society of Urological Pathology consensus classification of urothelial (transitional cell) neoplasms of the urinary bladder. Bladder Consensus Conference Committee. Am J Surg Pathol 1998;22:1435-48.

40. Wang C, Ross WT, Mysorekar IU. Urothelial generation and regeneration in development, injury, and cancer. Dev Dyn 2017;246:336-43.

41. Antoni S, Ferlay J, Soerjomataram I, Znaor A, Jemal A, Bray F. Bladder Cancer Incidence and Mortality: A Global Overview and Recent Trends. Eur Urol 2017;71:96-108.

42. Huang HY, Shariat SF, Sun TT, Lepor H, Shapiro E, Hsieh JT, et al. Persistent uroplakin expression in advanced urothelial carcinomas: implications in urothelial tumor progression and clinical outcome. Hum Pathol 2007;38:1703-13.

43. Wu RL, Osman I, Wu XR, Lu ML, Zhang ZF, Liang FX, et al. Uroplakin II gene is expressed in transitional cell carcinoma but not in bilharzial bladder squamous cell carcinoma: alternative pathways of bladder epithelial differentiation and tumor formation. Cancer Res 1998;58:1291-7.

44. Zupancic D, Romih R. Heterogeneity of uroplakin localization in human normal urothelium, papilloma and papillary carcinoma. Radiol Oncol 2013;47:338-45.

45. Zupancic D, Zakrajsek M, Zhou G, Romih R. Expression and localization of four uroplakins in urothelial preneoplastic 
lesions. Histochem Cell Biol 2011;136:491-500.

46. Achtstätter T, Moll R, Moore B, Franke WW. Cytokeratin polypeptide patterns of different epithelia of the human male urogenital tract: immunofluorescence and gel electrophoretic studies. J Histochem Cytochem 1985;33:415-26.

47. Schaafsma HE, Ramaekers FC, van Muijen GN, Ooms EC, Ruiter DJ. Distribution of cytokeratin polypeptides in epithelia of the adult human urinary tract. Histochemistry 1989;91:151-9.

48. Moll R, Schiller DL, Franke WW. Identification of protein IT of the intestinal cytoskeleton as a novel type I cytokeratin with unusual properties and expression patterns. J Cell Biol 1990;111:567-80.

49. Southgate J, Harnden P, Trejdosiewicz LK. Cytokeratin expression patterns in normal and malignant urothelium: a review of the biological and diagnostic implications. Histol Histopathol 1999;14:657-64.

50. McKenney JK, Desai S, Cohen C, Amin MB. Discriminatory immunohistochemical staining of urothelial carcinoma in situ and non-neoplastic urothelium: an analysis of cytokeratin 20, p53, and CD44 antigens. Am J Surg Pathol 2001;25:1074-8.

51. Van Batavia J, Yamany T, Molotkov A, Dan H, Mansukhani M, Batourina E, et al. Bladder cancers arise from distinct urothelial sub-populations. Nat Cell Biol 2014;16:982-91.

52. Lin C, Yin Y, Stemler K, Humphrey P, Kibel AS, Mysorekar IU, et al. Constitutive $\beta$-catenin activation induces male-specific tumorigenesis in the bladder urothelium. Cancer Res 2013;73:5914-25.

53. Shin K, Lim A, Zhao C, Sahoo D, Pan Y, Spiekerkoetter E, et al. Hedgehog signaling restrains bladder cancer progression by eliciting stromal production of urothelial differentiation factors. Cancer Cell 2014;26:521-33.

54. Doldo E, Costanza G, Agostinelli S, Tarquini C, Ferlosio A, Arcuri G, et al. Vitamin A, cancer treatment and prevention: the new role of cellular retinol binding proteins. Biomed Res Int 2015;2015:624627.

55. Mongan NP, Gudas LJ. Diverse actions of retinoid receptors in cancer prevention and treatment. Differentiation 2007; 75:853-70.

56. Liang FX, Bosland MC, Huang H, Romih R, Baptiste S, Deng FM, et al. Cellular basis of urothelial squamous metaplasia: roles of lineage heterogeneity and cell replacement. J Cell Biol 2005; 171:835-44.

57. Tang JE, Wang RJ, Zhong H, Yu B, Chen Y. Vitamin A and risk of bladder cancer: a meta-analysis of epidemiological studies. World J Surg Oncol 2014;12:130.

58. Mahmoud LA, Robinson WA. Vitamin A levels in human bladder cancer. Int J Cancer 1982;30:143-5.

59. Wu S, Liu Y, Michalek JE, Mesa RA, Parma DL, Rodriguez $\mathrm{R}$, et al. Carotenoid intake and circulating carotenoids are inversely associated with the risk of bladder cancer: A doseresponse meta-analysis. Adv Nutr 2020;11:630-43.

60. Zupancic D, Korac-Prlic J, Kreft ME, Frankovic L, Vilovic K, Jeruc J, et al. Vitamin A rich diet diminishes early urothelial carcinogenesis by altering retinoic acid signaling. Cancers (Basel) 2020;12:1712.

61. Simmons DP, Peach ML, Friedman JR, Green MM, Nicklaus MC, De Luca LM. Evidence that sequence homologous region in LRAT-like proteins possesses anti-proliferative activity and DNA binding properties: translational implications and mechanism of action. Carcinogenesis 2006;27:693707

62. Boorjian S, Tickoo SK, Mongan NP, Yu H, Bok D, Rando RR, et al. Reduced lecithin: retinol acyltransferase expression correlates with increased pathologic tumor stage in bladder can- cer. Clin Cancer Res 2004;10:3429-37.

63. van de Merwe JP, Nordling J, Bouchelouche P, Bouchelouche K, Cervigni M, Daha LK, et al. Diagnostic criteria, classification, and nomenclature for painful bladder syndrome/interstitial cystitis: an ESSIC proposal. Eur Urol 2008;53:60-7.

64. Homma Y. Interstitial cystitis, bladder pain syndrome, hypersensitive bladder, and interstitial cystitis/bladder pain syndrome - clarification of definitions and relationships. Int $\mathbf{J}$ Urol 2019;261:S20-4.

65. Lee G, Romih R, Zupancic D. Cystitis: from urothelial cell biology to clinical applications. Biomed Res Int 2014;2014:473536.

66. Zupancic D, Jezernik K, Vidmar G. Effect of melatonin on apoptosis, proliferation and differentiation of urothelial cells after cyclophosphamide treatment. J Pineal Res 2008;44:299306.

67. Kyung YS, Park HY, Lee G. Preservation of uroplakins by 2mercaptoethanesulfonate in cyclophosphamide-induced rat cystitis. Arch Toxicol 2011;85:51-7.

68. Birder L, Andersson KE. Urothelial signaling. Physiol Rev 2013;93:653-80.

69. Clapham DE, Julius D, Montell C, Schultz G. International Union of Pharmacology. XLIX. Nomenclature and structurefunction relationships of transient receptor potential channels. Pharmacol Rev 2005;57:427-50.

70. Merrill L, Gonzalez EJ, Girard BM, Vizzard MA. Receptors, channels, and signalling in the urothelial sensory system in the bladder. Nat Rev Urol 2016;13:193-204.

71. Charrua A, Cruz CD, Cruz F, Avelino A. Transient receptor potential vanilloid subfamily 1 is essential for the generation of noxious bladder input and bladder overactivity in cystitis. J Urol 2007;177:1537-41.

72. Lazzeri M, Vannucchi MG, Zardo C, Spinelli M, Beneforti P, Turini D, et al. Immunohistochemical evidence of vanilloid receptor 1 in normal human urinary bladder. Eur Urol 2004;46:792-8.

73. Yamada T, Ugawa S, Ueda T, Ishida Y, Kajita K, Shimada S. Differential localizations of the transient receptor potential channels TRPV4 and TRPV1 in the mouse urinary bladder. J Histochem Cytochem 2009;57:277-87.

74. Dornelles FN, Andrade EL, Campos MM, Calixto JB. Role of CXCR2 and TRPV1 in functional, inflammatory and behavioural changes in the rat model of cyclophosphamideinduced haemorrhagic cystitis. Br J Pharmacol 2014;171:45267.

75. Park JS, Jung HD, Cho YS, Jin MH, Hong CH. Neonatal bladder irritation is associated with vanilloid receptor TRPV1 expression in adult rats. Int Neurourol J 2018;22:169-76.

76. Yu W, Hill WG, Apodaca G, Zeidel ML. Expression and distribution of transient receptor potential (TRP) channels in bladder epithelium. Am J Physiol Renal Physiol 2011;300:F49-59.

77. Everaerts W, Sepúlveda MR, Gevaert T, Roskams T, Nilius B, De Ridder D. Where is TRPV1 expressed in the bladder, do we see the real channel? Naunyn Schmiedebergs Arch Pharmacol 2009;379:421-5.

78. Ikeda Y, Birder L, Buffington C, Roppolo J, Kanai A. Mucosal muscarinic receptors enhance bladder activity in cats with feline interstitial cystitis. J Urol 2009;181:1415-22.

79. Sánchez-Freire V, Blanchard MG, Burkhard FC, Kessler TM, Kellenberger S, Monastyrskaya K. Acid-sensing channels in human bladder: expression, function and alterations during bladder pain syndrome. J Urol 2011;186:1509-16.

80. Janssen DA, Jansen CJ, Hafmans TG, Verhaegh GW, Hoenderop JG, Heesakkers JP, et al. TRPV4 channels in the 
human urogenital tract play a role in cell junction formation and epithelial barrier. Acta Physiol (Oxf) 2016;218:38-48.

81. Sterle I, Zupancic D, Romih R. Correlation between Urothelial differentiation and sensory proteins P2X3, P2X5, TRPV1, and TRPV4 in normal urothelium and papillary carcinoma of human bladder. Biomed Res Int. 2014;2014:805236.

82. Everaerts W, Zhen X, Ghosh D, Vriens J, Gevaert T, Gilbert JP, et al. Inhibition of the cation channel TRPV4 improves bladder function in mice and rats with cyclophosphamideinduced cystitis. Proc Natl Acad Sci USA 2010;107:19084-9.

83. Charrua A, Cruz CD, Jansen D, Rozenberg B, Heesakkers J, Cruz F. Co-administration of transient receptor potential vanilloid 4 (TRPV4) and TRPV1 antagonists potentiate the effect of each drug in a rat model of cystitis. BJU Int 2015;115:452-60.

84. Janssen DA, Hoenderop JG, Jansen KC, Kemp AW, Heesakkers JP, Schalken JA. The mechanoreceptor TRPV4 is localized in adherence junctions of the human bladder urothelium: a morphological study. J Urol 2011;186:1121-7.

85. Birder LA, Ruan HZ, Chopra B, Xiang Z, Barrick S, Buffington CA, et al. Alterations in $\mathrm{P} 2 \mathrm{X}$ and $\mathrm{P} 2 \mathrm{Y}$ purinergic receptor expression in urinary bladder from normal cats and cats with interstitial cystitis. Am J Physiol Renal Physiol 2004;287:F1084-91

86. Svennersten K, Hallen-Grufman K, de Verdier PJ, Wiklund NP, Poljakovic M. Localization of P2X receptor subtypes 2, 3 and 7 in human urinary bladder. BMC Urol 2015;15:81.

87. Vial C, Evans RJ. P2X receptor expression in mouse urinary bladder and the requirement of $\mathrm{P} 2 \mathrm{X}(1)$ receptors for functional $\mathrm{P} 2 \mathrm{X}$ receptor responses in the mouse urinary bladder smooth muscle. Br J Pharmacol 2000;131:1489-95.

88. Dunton CL, Purves JT, Hughes FM, Jin H, Nagatomi J. Elevated hydrostatic pressure stimulates ATP release which mediates activation of the NLRP3 inflammasome via P2X. Int Urol Nephrol 2018;50:1607-17.

89. Wang EC, Lee JM, Ruiz WG, Balestreire EM, von Bodungen $\mathrm{M}$, Barrick S, et al. ATP and purinergic receptor-dependent membrane traffic in bladder umbrella cells. J Clin Invest 2005;115:2412-22.

90. Kim JC, Yoo JS, Park EY, Hong SH, Seo SI, Hwang TK. Muscarinic and purinergic receptor expression in the urothelium of rats with detrusor overactivity induced by bladder outlet obstruction. BJU Int 2008;101:371-5.

91. Ferguson AC, Sutton BW, Boone TB, Ford AP, Munoz A. Inhibition of urothelial $\mathrm{P} 2 \mathrm{X} 3$ receptors prevents desensitization of purinergic detrusor contractions in the rat bladder. BJU Int 2015;116:293-301.

92. Studeny S, Torabi A, Vizzard MA. P2X2 and P2X3 receptor expression in postnatal and adult rat urinary bladder and lumbosacral spinal cord. Am J Physiol Regul Integr Comp Physiol 2005;289:R1155-68.

93. Liu M, Xu YF, Feng Y, Yang FQ, Luo J, Zhai W, et al. Epigallocatechin gallate attenuates interstitial cystitis in human bladder urothelium cells by modulating purinergic receptors. J Surg Res 2013;183:397-404.
94. Tempest HV, Dixon AK, Turner WH, Elneil S, Sellers LA, Ferguson DR. P2X and P2X receptor expression in human bladder urothelium and changes in interstitial cystitis. BJU Int 2004;93:1344-8.

95. Sun Y, Chai TC. Up-regulation of P2X3 receptor during stretch of bladder urothelial cells from patients with interstitial cystitis. J Urol 2004;171:448-52.

96. Sun Y, Keay S, Lehrfeld TJ, Chai TC. Changes in adenosine triphosphate-stimulated ATP release suggest association between cytokine and purinergic signaling in bladder urothelial cells. Urology 2009;74:1163-8.

97. Yu W, Hill WG. Defining protein expression in the urothelium: a problem of more than transitional interest. Am J Physiol Renal Physiol 2011;301:F932-42.

98. Kreft ME, Romih R, Kreft M, Jezernik K. Endocytotic activity of bladder superficial urothelial cells is inversely related to their differentiation stage. Differentiation 2009;77:48-59.

99. Romih R, Jezernik K. Endocytosis during postnatal differentiation in superficial cells of the mouse urinary bladder epithelium. Cell Biol Int 1994;18:663-8.

100. Liao Y, Tham DKL, Liang FX, Chang J, Wei Y, Sudhir PR, et al. Mitochondrial lipid droplet formation as a detoxification mechanism to sequester and degrade excessive urothelial membranes. Mol Biol Cell 2019;30:2969-84.

101. Tratnjek L, Romih R, Kreft ME. Differentiation-dependent rearrangements of actin filaments and microtubules hinder apical endocytosis in urothelial cells. Histochem Cell Biol 2017;148:143-56.

102. Khandelwal P, Ruiz WG, Apodaca G. Compensatory endocytosis in bladder umbrella cells occurs through an integrin-regulated and RhoA- and dynamin-dependent pathway. EMBO J 2010;29:1961-75.

103. Winder M, Vesela R, Aronsson P, Patel B, Carlsson T. Autonomic receptor-mediated regulation of production and release of nitric oxide in normal and malignant human urothelial cells. Basic Clin Pharmacol Toxicol 2017;121:257-65.

104. Hoffman DP, Shtengel G, Xu CS, Campbell KR, Freeman M, Wang L, et al. Correlative three-dimensional super-resolution and block-face electron microscopy of whole vitreously frozen cells. Science 2020;367:eaaz5357.

105. Möbius W, Posthuma G. Sugar and ice: Immunoelectron microscopy using cryosections according to the Tokuyasu method. Tissue Cell 2019;57:90-102.

106. Kreft ME, Di Giandomenico D, Beznoussenko GV, Resnik N, Mironov AA, Jezernik K. Golgi apparatus fragmentation as a mechanism responsible for uniform delivery of uroplakins to the apical plasma membrane of uroepithelial cells. Biol Cell 2010;102:593-607.

107. Kreft ME, Robenek H. Freeze-fracture replica immunolabelling reveals urothelial plaques in cultured urothelial cells. PLoS One 2012;7:e38509.

108. Zupancic D, Kreft ME, Sterle I, Romih R. Combined lectinand immuno-histochemistry (CLIH) for applications in cell biology and cancer diagnosis: Analysis of human urothelial carcinomas. Eur J Histochem 2020;64:3141.

Received for publication: 11 March 2021. Accepted for publication: 19 March 2021.

This work is licensed under a Creative Commons Attribution-NonCommercial 4.0 International License (CC BY-NC 4.0).

(C) Copyright: the Author(s), 2021

Licensee PAGEPress, Italy

European Journal of Histochemistry 2021; 65:3242

doi:10.4081/ejh.2021.3242 